\title{
Nanoparticle type effects on the scratch resistance of polyethylene-based nanocomposites
}

\author{
Abdulaziz Salem Alghamdi* \\ Mechanical Engineering Department, College of Engineering, University of Hail, Hail, Saudi Arabia
}

\section{ART ICLE INFO}

\section{Article history:}

Received 21 December 2016

Received in revised form

8 February 2017

Accepted 8 February 2017

\section{Keywords:}

Polymer

Polyethylene

Nanocomposite

Scratch

Nanoparticle

\begin{abstract}
A B S T R A C T
The purpose of this paper is to investigate the effect of nanoparticle type on the scratch resistance of polyethylene-based nanocomposites at two ambient temperatures and various scratch velocities. An in-house pre-mix procedure is used to enhance the scratch resistance of polyethylene blend by the addition of three different types of nanoparticles, which are compatible with the host matrix. The results showed a good dispersion of nanoparticles into the host material matrix. The scratch resistance of polyethylene-based nanocomposites is significantly influenced by the type of nanoparticles at both testing temperatures. The addition of low volume fraction $(0.5 \mathrm{wt} . \%)$ of nanoclay and CNT showed a significant increase in the scratch resistance of nanocomposite material at the highest scratching velocity for both testing temperatures. While, slight effect of the embedding of nanoclay was indicated at low scratch velocity. The addition of $0.5 \mathrm{wt} \% \mathrm{CB}$ resulted in a reduction in the scratch resistance at all testing parameters.
\end{abstract}

(C) 2017 The Authors. Published by IASE. This is an open access article under the CC BY-NC-ND license (http://creativecommons.org/licenses/by-nc-nd/4.0/).

\section{Introduction}

Scratch resistance of polymer materials is an important property in many demanding applications such as coating and lining in automotive, protecting layers in touch screens for electronic devices and optical products. Therefore, it is important to develop an existing material such as polyethylene to increase its scratch resistance and subsequently its applications. Ultra-high molecular weight polyethylene (UHMWPE) is a high performance thermoplastic with outstanding mechanical properties, such as high wear strength, chemical resistance and high toughness, which provide not only practical benefits but also scientific interest (Kelly, 2002; Lucas et al., 2011; Lim et al., 2005). However, it's extremely high molecular weight, and subsequent high viscosity, raises difficulties in processing using standard techniques, such as twin screw extrusion and compression moulding. Reducing the viscosity of UHMWPE is an effective method of avoiding these processing difficulties. Blending UHMWPE with other polymers that have lower viscosity, such as high density polyethylene (HDPE), can therefore be used to improve

\footnotetext{
* Corresponding Author.

Email Address: asbg945@hotmail.com

https://doi.org/10.21833/ijaas.2017.04.001

2313-626X/@ 2017 The Authors. Published by IASE.

This is an open access article under the CC BY-NC-ND license

(http://creativecommons.org/licenses/by-nc-nd/4.0/)
}

processability. UHMWPE/HDPE blends are of current interest owing to the improvement in the processability and creep resistance compared with UHMWPE (Xue et al., 2006; Sui et al., 2009). HDPE has a similar structure to UHMWPE but with lower molecular chain length, however, it exhibits lower wear resistance, yield strength and toughness than UHMWPE (Kelly, 2002). This reduction in performance on adding HDPE to UHMWPE can potentially be mitigated, whilst retaining the improved processability, by the addition of nanoreinforcement, which has been shown to improve the mechanical performance of polyethylene (Chen et al., 2012; Ren et al., 2012; Kontou and Niaounakis, 2006; Zoo et al., 2004; Zhenhua and Yunxuan, 2012; Stoeffler et al., 2011; Tang et al., 2003; Kanagaraj et al., 2007; Alghamdi et al., 2013a;b;2014;2015).

Scratch resistance for materials can be highly affected by testing conditions such as load (Krupička et al., 2003; Wong et al., 2004a; Zhang and Li, 2003) scratch velocity (Krupička et al., 2003; Zhang and Li, 2003; Gauthier and Schirrer, 2000) and temperature, where, the effect of polymer softening and loss of the filler-matrix interaction can lead to significant degradation in the mechanical properties of the filled polymers (Gauthier and Schirrer, 2000; Jardret and Morel, 2003; Cao et al., 2011). Material characteristics such as ductility (Browning et al., 2006; Hadal and Misra, 2005), crystallinity (Surampadi et al., 2007; Moghbelli et al., 2008), hardness (Rodriguez et al., 2007; Briscoe et al., 
1996) and surface roughness (Wong et al., 2004b) can significantly influence the scratch resistance of polymers. Kurkcu et al. (2014) pointed out that the scratch resistance of polymers can be enhanced by the incorporation of hard filler. In a previous work (Alghamdi et al., 2015), it was found that the addition of MWCNT and nanoclay can significantly increase the hardness, elastic modulus and indentation resistance of polyethylene-based nanocomposites. This was attributed to the presence of nanofillers with high strength and surface area to volume ratios. Therefore, the objective of this work is to enhance the scratch resistance of polyethylene by the embedding of low volume fraction of nanoparticles into the matrix using simple processing method. This can increase the possibility to develop polymer with high scratch resistance and low cost. Based on a previous work, the effect of the degree of crystallinity is negligible for the blends and the nanocomposites, as no significant change was observed (Alghamdi et al., 2015).

\section{Experimental methods}

\subsection{Materials}

The materials tested in this study were UHMWPE/HDPE blended polymers with three types of nanofillers, which are carbon black (CB), nanoclay and carbon nanotubes (CNTs). Nascent UHMWPE powders (Sabic®UHMWPE3548) were purchased from SABIC (Dhahran, Saudi Arabia) which had an average molecular weight of $3 \times 10^{6} \mathrm{~mol} / \mathrm{g}$. HDPE powders (ExxonMobil TM HDPE HMA014) were purchased from ICO Ltd (ExxonMobil Chemical Europe, Belgium). Carbon black (CB) powder with the commercial product name, black pearls $(\AA 4040$ (BP4040) and average particle diameter of $28 \mathrm{~nm}$ were provided by the Cabot Corporation (Cabot Corporation, USA). Natural hectorite nanoclay was supplied by Elements specialties (Elements Specialties, USA). Multi-wall Nanotubes (MWNT) with diameters in the range of $5 \mathrm{~nm}$ to $50 \mathrm{~nm}$, were provided by Nanocyl (Nanocyl, Belgium). Butylated hydroxytoluene and Tris (nonylphenyl) phosphate, supplied by Sigma-Aldrich (Sigma-Aldrich, UK), were used as primary and secondary antioxidants, to maintain the long term thermal stability and melt processing stability, respectively.

\subsection{Processing}

An in-house pre-mix technology was used to incorporate the nanofillers into the UHMWPE and HDPE powders. A twin-screw extruder was then used to blend the UHMWPE and HDPE powders premixed with $\mathrm{CB}$, carbon nanotubes (CNT) or nanoclay to form Nano-filled UHMWPE/HDPE blends with a constant volume fraction of 0.5 wt. $\%$ each. A blend of 75 wt. \% UHMWPE and 25 wt. \% HDPE, abbreviated to $\mathrm{U} 75 \mathrm{H} 25$, was used as the hybrid PE matrix to accommodate the nanofillers. During processing, the mixing temperature was controlled using five zones from feeding port to die; the processing parameters are shown in Table 1. Compression moulding was used to mould the Nano composite materials. The raw material was placed into a square mould (100 X $100 \times 1.65 \mathrm{~mm}$ ), and then heated to $190^{\circ} \mathrm{C}$, which is higher than the melting point of the composite (approximately $135^{\circ} \mathrm{C}$ ). Various mould pressures $(154,232,309$, and $386 \mathrm{MPa})$ were investigated to optimize the properties of the material such as hardness and crystallinity. Various holding times at maximum pressure $(10,15$ and 30 minutes) were also used to identify the most appropriate moulding parameters. The optimal moulding pressure and holding time were $309 \mathrm{MPa}$ and 15 minutes respectively, which resulted in the highest values of hardness and crystallinity. After compression moulding, the mould was cooled to room temperature using water. Then, the specimens were cut from the plaques into a square shape of $10 \times 10$ $\mathrm{mm}$ with $1.65 \mathrm{~mm}$ thickness.

Table 1: Processing method parameters

\begin{tabular}{cccc}
\hline Extruder Speed $(\mathrm{rpm})$ & Processing Temperature $\left({ }^{\circ} \mathrm{C}\right)$ & Cooling \\
\hline & Zone 1 & 180 & \\
& Zone 2 & 190 & \\
\multirow{2}{*}{400} & Zone 3 & 200 & \multirow{2}{*}{ water } \\
& Zone 4 & 210 & \\
& Die & 220 & \\
\hline
\end{tabular}

\subsection{Material testing and characterization}

In order to characterize the Nano filler dispersion and the microstructure of the U75H25 nanocomposites, several experimental techniques were used. These included Differential Scanning Calorimetry (DSC), Scanning Electron Microscopy (SEM) and Transmission Electron Microscopy (TEM). The details of these techniques are discussed in this section.

Differential Scanning Calorimetry (DSC), (TA instruments, Shimadzu DSC60) was used to analyze the effect of different compression moulding parameters and nanoparticle type on the crystallinity of the blend and nanocomposites. The specimens, with average mass of $5 \pm 0.2 \mathrm{mg}$, were sealed in aluminium pans and heated from 20 to $180^{\circ} \mathrm{C}$ at a rate of $10^{\circ} \mathrm{C}$ per minute. The mass fraction degree of crystallinity was then determined by comparing the heat of fusion with that for fully crystalline polyethylene at the equilibrium melting point (290 kJ/kg) (Humbert et al., 2009). The surface morphology was investigated using a LEO 440 Scanning Electron Microscopy (SEM) from Leo Electron Microscopy Ltd (Cambridge, UK), and Philips XL30 ESEM-FEG from FEI Company 
(Eindhoven, The Netherlands). The dispersion of nanoparticles was studied after fracturing the samples in liquid nitrogen, then coating them using platinum. A JEOL 2000FX Transmission Electron Microscopy (TEM) from JEOL Ltd. (Welwyn Garden, UK) was used to analyze the dispersion of nanoparticles into the blend matrix.

The microscratch test was performed on the specimens at controlled machine chamber temperatures of 22.8 and 45, using a Nano Test machine 600 from Micro Materials Ltd (Wrexham, UK). A diamond Rockwell tip, with $200 \mu \mathrm{m}$ radius, was used to make at least 5 scratches with scratch parameters as shown in Table 2. The results were plotted using Excel.

\section{Results and discussion}

\subsection{Nanoparticle dispersion}

Nanoparticle dispersion is a very important factor in the manufacture of nanocomposites that can affect the mechanical and rheological properties of the composite. Scanning electron microscopy (SEM) and transmission electron microscopy (TEM) were used to analyze nanoparticle dispersion in the
U75H25 matrix, as shown in Fig. 1 and Fig. 2. It can be seen that there are homogenous dispersions of CB and CNT at the constant volume fraction (0.5 wt. \%), with no large aggregates of nanoparticles, Fig. 1(a) and Fig. 1(b). Fig. 1(c) shows an individual nanoclay layer, which indicated by the arrow on the image. Further evidence of the well dispersion of CNT and CB nanoparticle can be seen in the TEM images in Fig. 2(a) and Fig. 2(b). Fig. 2(c) shows nanoclay layers in the blend matrix, which are the dark regions on the image. This image can be used as evidence for the very well exfoliation of the nanoclay layers in the polymer matrix. The exfoliation and dispersion of clay platelets in the polymer matrix are important issues to achieve the desired mechanical properties, especially for a non-polar matrix such as polyethylene (Durmus et al., 2007).

Table 2: Scratch test parameters

\begin{tabular}{ccccc}
\hline Experiment & 1 & 2 & 3 & 4 \\
\hline Scratch Velocity $(\mu \mathrm{m} / \mathrm{s})$ & 5 & 10 & 15 & 15 \\
Load $(\mathrm{mN})$ & 30 & 30 & 30 & 30 \\
Scratch Length $(\mu \mathrm{m})$ & 150 & 150 & 150 & 150 \\
Loading Rate $(\mathrm{mN} / \mathrm{s})$ & 2.97 & 2.97 & 2.97 & 2.97 \\
Temperature $\left({ }^{\circ} \mathrm{C}\right)$ & 22.8 & 22.8 & 22.8 & 45 \\
\hline
\end{tabular}

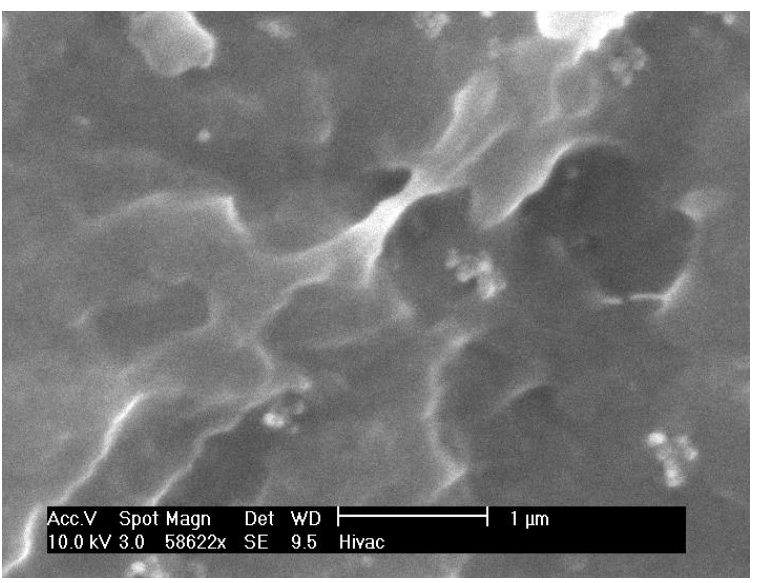

a

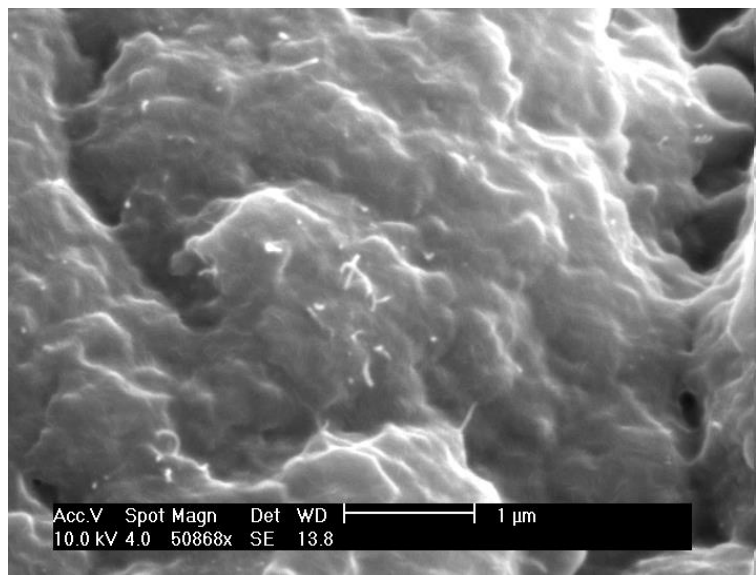

b

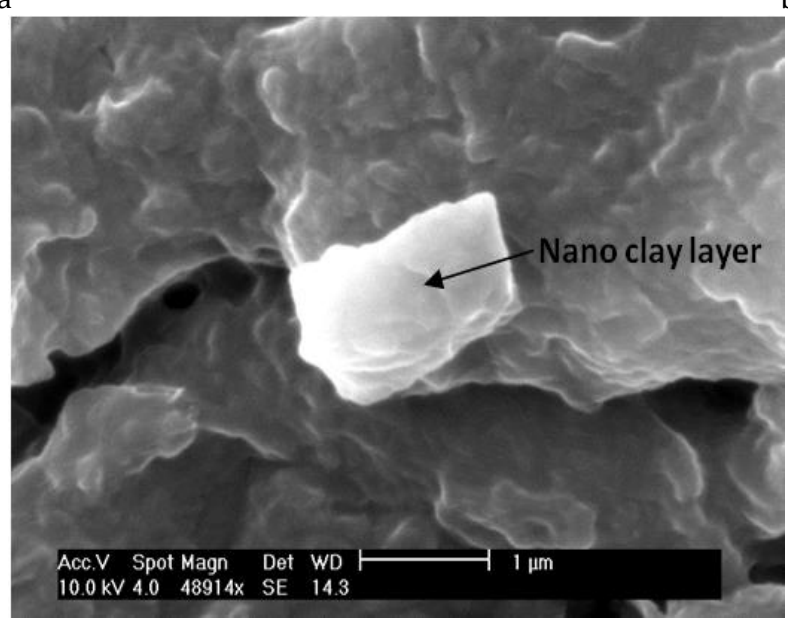

C

Fig. 1: SEM images for the dispersion of nanoparticles in the U75H25 matrix: a) $0.5 w t . \%$ CB, b) $0.5 w t . \%$ CNT and c) 0.5 wt. $\%$ Clay 


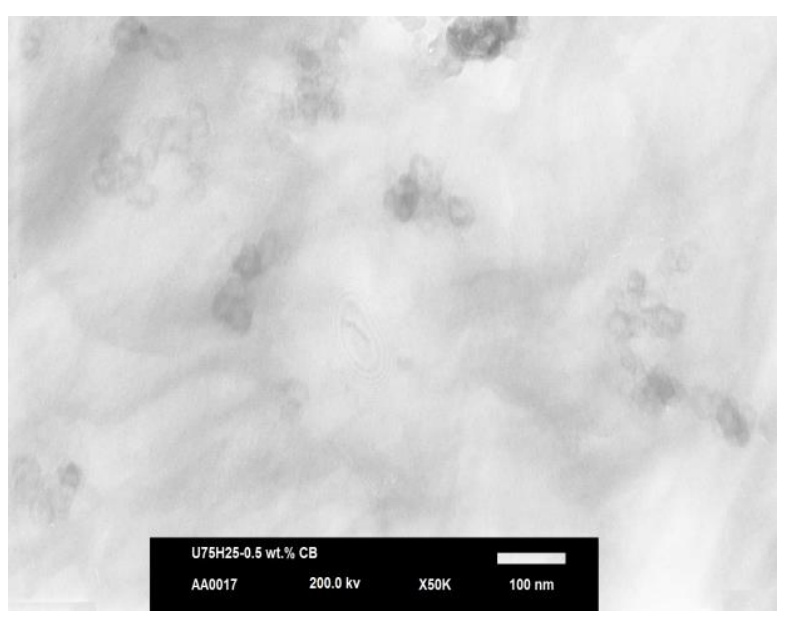

a

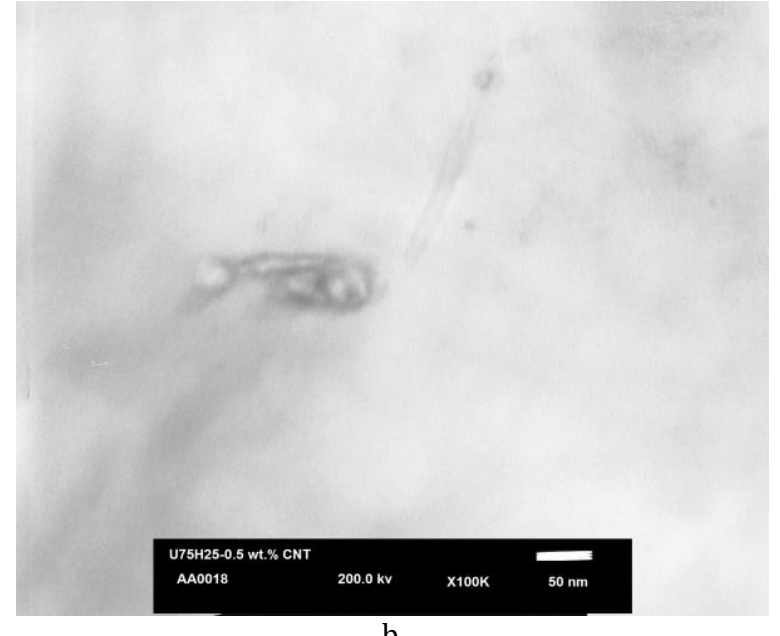

$\mathrm{b}$

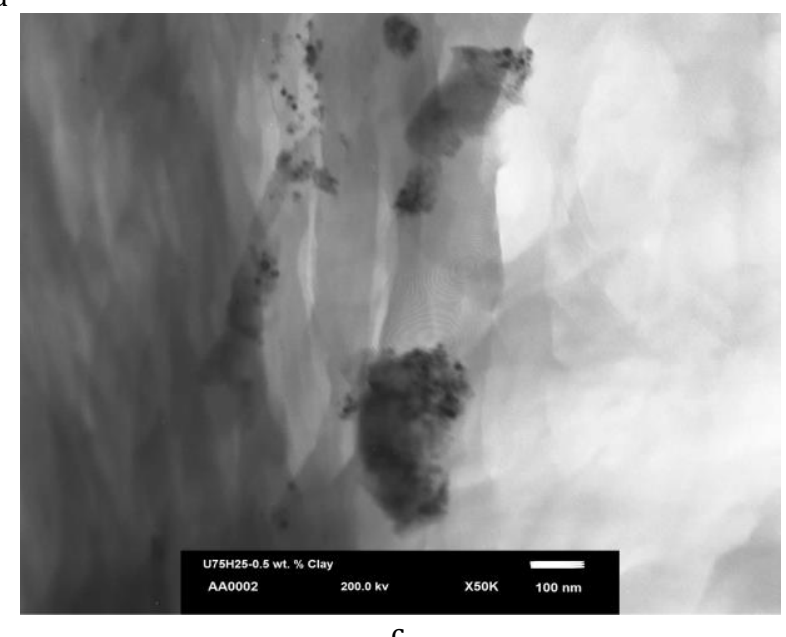

Fig. 2: TEM images for the dispersion of nanoparticles in the U75H25 matrix: a) $0.5 w t . \%$ CB, b) $0.5 w t . \%$ CNT and c) 0.5 wt. $\%$ Clay

\subsection{Nanoparticle type and temperature effects}

Fig. 3 shows the effect of nanoparticle type on the scratch resistant of polyethylene-based nanocomposites at two different ambient temperatures and constant scratch velocity. It can be seen that the addition of CNT and nanoclay particles resulted in a significant increase in the scratch resistance of the polyethylene-based nanocomposites at both testing temperatures. The resistance increased proportionally with scratch depth. This can be proposed to the well interaction between nanoparticles and polymer matrix. Adversely, the embedding of $\mathrm{CB}$ nanoparticles into the polymer matrix resulted in a significant reduction in the scratch resistance of the polyethylene Nano composite at both testing temperatures. This can be attributed to the poor interaction between matrix and nanofillers, which means that the load or stress is not completely transferred to the particles. Since no chemical modification was used in the preparation of the nanoparticles used in this study, no interaction between the nanoparticle and the polymer matrix is likely to occur. This can negatively affects the properties of the polymer composite, which might even be less than that of the neat polymer matrix.
Micro-cracks and voids can be formed ahead the tool tip during scratching of polyethylene-based nanocomposites. The presence of $\mathrm{CB}$ nanoparticles with weak interaction with the polymer matrix can increase the crack initiation and leads to a reduction in the scratch resistance and gives smooth scratching (Blackman et al., 2016). The embedding of CNT or clay nanoparticles resulted in less cracks initiation owing to the good interaction between the filler and the polyethylene matrix. The existence of these nanoparticles resulted in additional effect on the scratch mechanisms ahead and beneath the tool tip, which leads to more scratching resistance.

\subsection{Effects of scratching velocity}

Fig. 4 shows the effect of lower scratching velocity on the scratch resistance of polyethylenebased nanocomposites. It can be seen that the embedding of small volume fraction of nanofillers into the polymer matrix has no effect on the scratch resistance at low scratching velocity $(5 \mu \mathrm{m} / \mathrm{s})$. By increasing scratching velocity to $10 \mu \mathrm{m} / \mathrm{s}$, the addition of $0.5 \mathrm{wt} . \%$ nanoclay resulted in a better scratch resistance behaviour. This can be attributed to the one dimensional shape of the clay platelet, which affects the motion mechanisms of polymer chains. At higher scratching velocity (as seen in Fig. 
$3)$, the addition of CNT and nanoclay resulted in a noticed improvement in the scratch resistance, while the addition of $\mathrm{CB}$ resulted in a significant reduction in the scratch resistance. This can be proposed to the three dimensional shape of the CB nanoparticles and

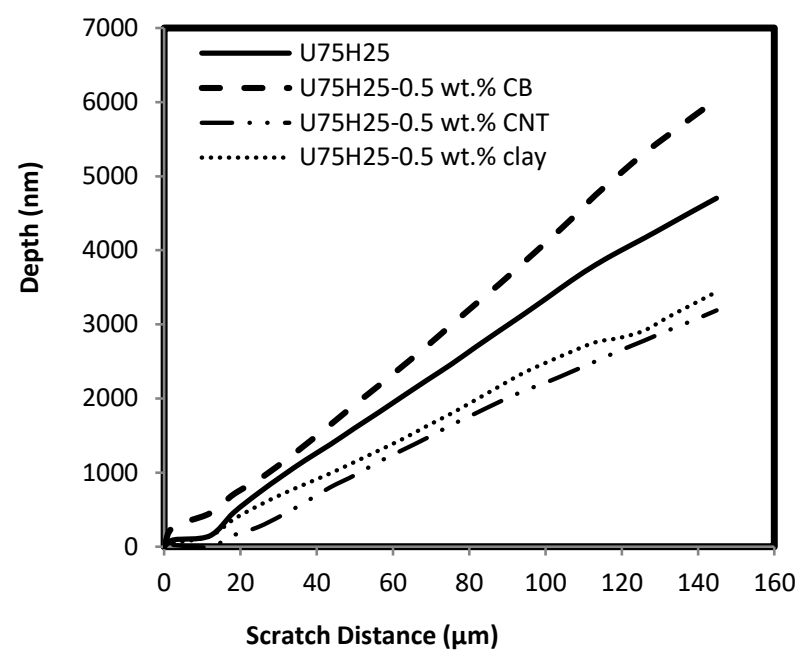

the weak interaction between particles and polymer matrix. The results can be used as evidence for the great influence of nanoparticle type on the scratch resistance of polyethylene-based nanocomposites at high scratching velocities.

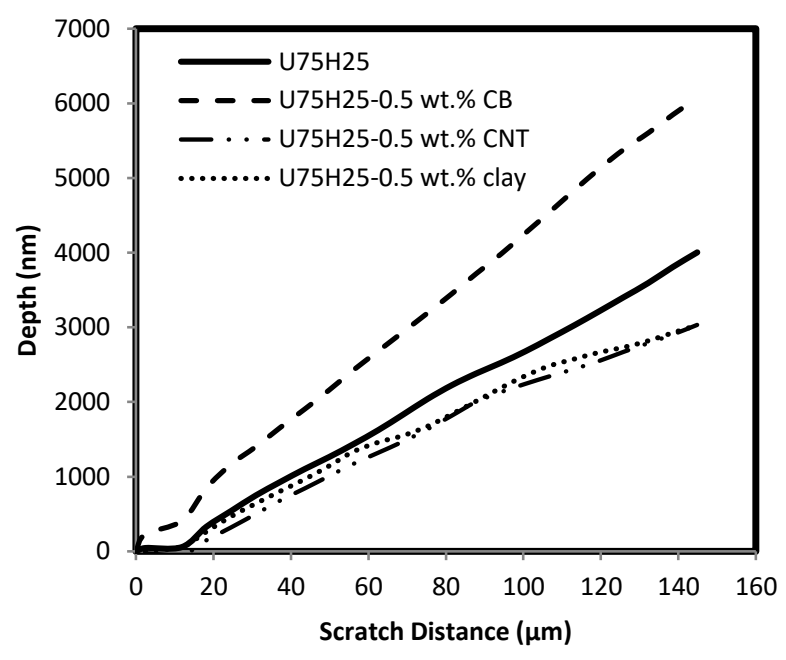

b

Fig. 3: Effect of nanoparticle type on the scratch resistance of polyethylene-based nanocomposites at: (a) $22.8{ }^{\circ} \mathrm{C}$ and (b) 45 ${ }^{\circ} \mathrm{C}$ (using $15 \mu \mathrm{m} / \mathrm{s}$ scratch velocity)

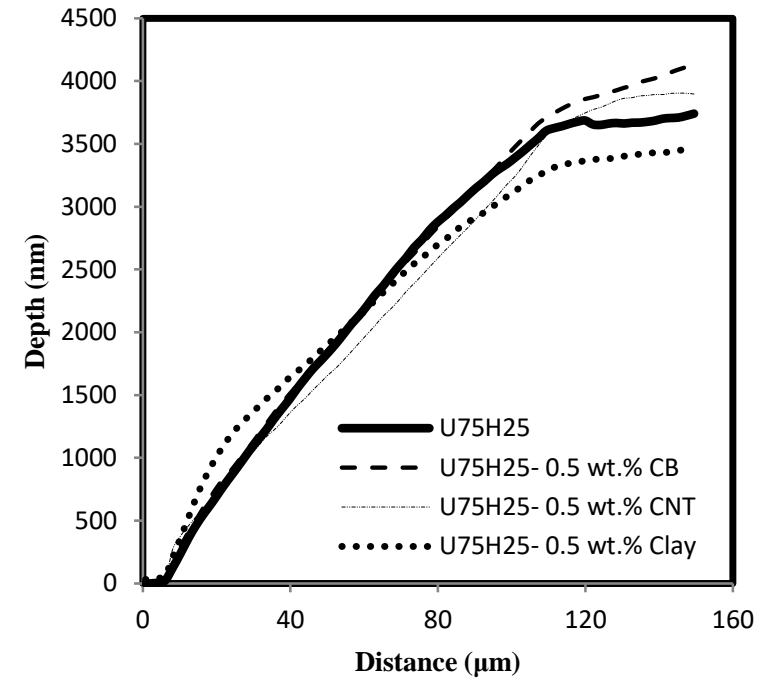

a

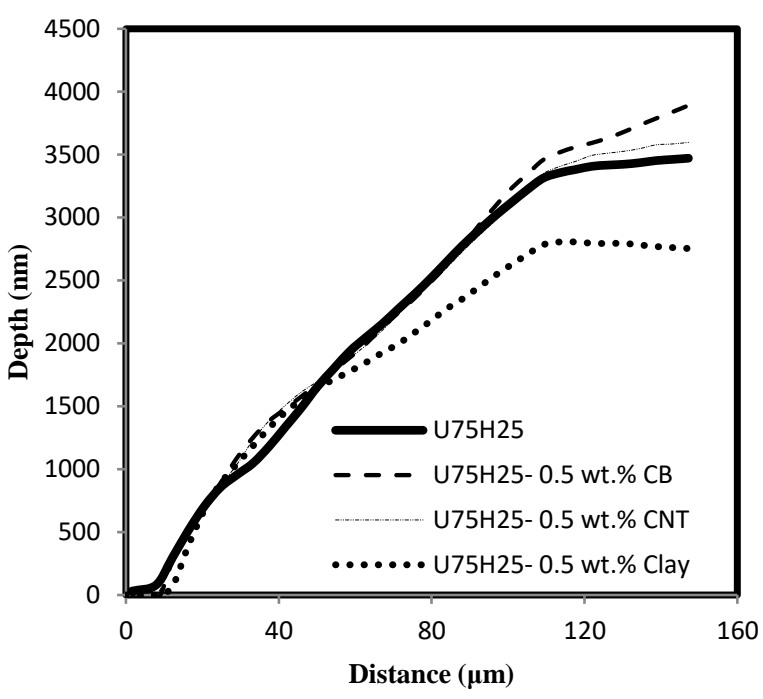

$\mathrm{b}$

Fig. 4: Effect of scratch velocity on the scratch resistance of polyethylene-based nanoparticles using: (a) $5 \mu \mathrm{m} / \mathrm{s}$ and (b) 10 $\mu \mathrm{m} / \mathrm{s}$ (at room temperature $=22.8^{\circ} \mathrm{C}$ )

\section{Conclusions}

In this paper, the effects of nanoparticle type on the scratch resistance of polyethylene-based nanocomposites were studied using micro scratch testing machine at various scratching velocity and two temperatures. The addition of small volume fraction of nanoparticle showed no effects on the scratch resistance at low scratching velocity $(5 \mu \mathrm{m} / \mathrm{s})$. At $15 \mu \mathrm{m} / \mathrm{s}$ scratching velocity, the addition of CNT or nanoclay resulted in a considerable improvement in the scratch resistance of polyethylene nanocomposites. Adversely, the embedding of three dimensional CB nanoparticles resulted in a significant reduction in the scratch resistance. These results showed clear correlation between nanoparticle type and scratch behaviour for polyethylene nanocomposites.

Similarly, the addition of CNT or nanoclay particles to polyethylene matrix resulted in an improvement in the scratch resistance at high testing temperature. Material softening has no effect on the scratch behaviour, however a slight reduction in the scratch depth is likely to occur. The addition of three dimensional CB nanoparticles to the polymer matrix showed significant reduction on the scratch resistance at both room and high temperature. This was attributed to the weak interaction between the matrix and nanofillers and the geometry of $\mathrm{CB}$ nanoparticles. 


\section{References}

Alghamdi A, Ashcroft I, and Song M (2015). High Temperature Effects On The Nanoindentation Behaviour Of Polyethylenebased Nanocomposites. International Journal of Computational Methods and Experimental Measurements, 3(2): 79-88.

Alghamdi AS, Ashcroft IA, and Song M (2014). Creep resistance of novel polyethylene/carbon black nanocomposites. International Journal of Materials Science and Engineering, 2(1): 1-5.

Alghamdi AS, Ashcroft IA, Song M, and Cai D (2013a). Nanoparticle type effects on heat generation during the plastic deformation of polyethylene nanocomposites. Polymer Testing, 32(8): 1502-1510.

Alghamdi AS, Ashcroft IA, Song M, and Cai D (2013b). Morphology and strain rate effects on heat generation during the plastic deformation of polyethylene/carbon black nanocomposites. Polymer Testing, 32(6): 1105-1113.

Blackman BRK, Hoult T, Patel Y, Steininger H, and Williams JG (2016). Steady-state scratch testing of polymers. Polymer Testing, 49: 38-45.

Briscoe BJ, Evans PD, Biswas SK, and Sinha SK (1996). The hardnesses of poly (methylmethacrylate). Tribology International, 29(2): 93-104.

Browning RL, Lim GT, Moyse A, Sue HJ, Chen H, and Earls JD (2006). Quantitative evaluation of scratch resistance of polymeric coatings based on a standardized progressive load scratch test. Surface and Coatings Technology, 201(6): 29702976.

Cao S, Wang X, and Wu Z (2011). Evaluation and prediction of temperature-dependent tensile strength of unidirectional carbon fiber-reinforced polymer composites. Journal of Reinforced Plastics and Composites, 30(9): 799-807.

Chen Y, Qi Y, Tai Z, Yan X, Zhu F, and Xue Q (2012). Preparation, mechanical properties and biocompatibility of graphene oxide/ultrahigh molecular weight polyethylene composites. European Polymer Journal, 48(6): 1026-1033.

Durmus A, Kasgoz A, and Macosko CW (2007). Linear low density polyethylene (LLDPE)/clay nanocomposites. Part I: Structural characterization and quantifying clay dispersion by melt rheology. Polymer, 48(15): 4492-4502.

Gauthier C and Schirrer R (2000). Time and temperature dependence of the scratch properties of poly (methylmethacrylate) surfaces. Journal of Materials Science, 35(9): 2121-2130.

Hadal RS and Misra RDK (2005). Scratch deformation behavior of thermoplastic materials with significant differences in ductility. Materials Science and Engineering: A, 398(1): $252-$ 261.

Humbert S, Lame 0, and Vigier G (2009). Polyethylene yielding behaviour: What is behind the correlation between yield stress and crystallinity?. Polymer, 50(15): 3755-3761.

Jardret V and Morel P (2003). Viscoelastic effects on the scratch resistance of polymers: relationship between mechanical properties and scratch properties at various temperatures. Progress in Organic Coatings, 48(2): 322-331.

Kanagaraj S, Varanda FR, Zhil'tsova TV, Oliveira MS, and Simões JA (2007). Mechanical properties of high density polyethylene/carbon nanotube composites. Composites Science and Technology, 67(15): 3071-3077.

Kelly JM (2002). Ultra-high molecular weight polyethylene. Journal of Macromolecular Science, Part C: Polymer Reviews, 42(3): 355-371.
Kontou E and Niaounakis M (2006). Thermo-mechanical properties of LLDPE/SiO 2 nanocomposites. Polymer, 47(4): 1267-1280.

Krupička A, Johansson M, and Hult A (2003). Use and interpretation of scratch tests on ductile polymer coatings. Progress in Organic Coatings, 46(1): 32-48.

Kurkcu P, Andena L, and Pavan A (2014). An experimental investigation of the scratch behaviour of polymers-2: Influence of hard or soft fillers. Wear, 317(1): 277-290.

Lim KLK, Ishak ZA, Ishiaku US, Fuad AMY, Yusof AH, Czigany T, and Ogunniyi DS (2005). High-density polyethylene/ultrahigh-molecular-weight polyethylene blend. I. The processing, thermal, and mechanical properties. Journal of Applied Polymer Science, 97(1): 413-425.

Lucas ADA, Ambrósio JD, Otaguro H, Costa LC, and Agnelli JA (2011). Abrasive wear of HDPE/UHMWPE blends. Wear, 270(9): 576-583.

Moghbelli E, Browning RL, Boo WJ, Hahn SF, Feick LJE, and Sue HJ (2008). Effects of molecular weight and thermal history on scratch behavior of polypropylene thin sheets. Tribology International, 41(5): 425-433.

Ren PG, Di YY, Zhang Q, Li L, Pang H, and Li ZM (2012). Composites of Ultrahigh-Molecular-Weight Polyethylene with Graphene Sheets and/or MWCNTs with Segregated Network Structure: Preparation and Properties. Macromolecular Materials and Engineering, 297(5): 437-443.

Rodriguez J, Rico A, and Soria V (2007). Tribological properties of commercial optical disks estimated from nanoindentation and scratch techniques. Wear, 263(7): 1545-1550.

Stoeffler K, Lafleur PG, Perrin-Sarazin F, Bureau MN, and Denault J (2011). Micro-mechanisms of deformation in polyethylene/clay micro-and nanocomposites. Composites Part A: Applied Science and Manufacturing, 42(8): 916-927.

Sui G, Zhong WH, Ren X, Wang XQ, and Yang XP (2009). Structure, mechanical properties and friction behavior of UHMWPE/HDPE/carbon nanofibers. Materials Chemistry and Physics, 115(1): 404-412.

Surampadi NL, Pesacreta TC, and Misra RDK (2007). The determining role of scratch indenter radius on surface deformation of high density polyethylene and calcium carbonate-reinforced composite. Materials Science and Engineering: A, 456(1): 218-229.

Tang W, Santare MH, and Advani SG (2003). Melt processing and mechanical property characterization of multi-walled carbon nanotube/high density polyethylene (MWNT/HDPE) composite films. Carbon, 41(14): 2779-2785.

Wong JS, Sue HJ, Zeng KY, Li RK, and Mai YW (2004a). Scratch damage of polymers in nanoscale. Acta Materialia, 52(2): 431443.

Wong M, Lim GT, Moyse A, Reddy JN, and Sue HJ (2004b). A new test methodology for evaluating scratch resistance of polymers. Wear, 256(11): 1214-1227.

Xue Y, Wu W, Jacobs O, and Schädel B (2006). Tribological behaviour of UHMWPE/HDPE blends reinforced with multiwall carbon nanotubes. Polymer Testing, 25(2): 221-229.

Zhang SL and Li JCM (2003). Slip process of stick-slip motion in the scratching of a polymer. Materials Science and Engineering: A, 344(1): 182-189.

Zhenhua L and Yunxuan L (2012). Mechanical and tribological behaviour of UHMWPE/HDPE blends reinforced with SBS. Polymer-Plastics Technology and Engineering, 51(7): 750753.

Zoo YS, An JW, Lim DP, and Lim DS (2004). Effect of carbon nanotube addition on tribological behavior of UHMWPE. Tribology Letters, 16(4): 305-309. 